\title{
Multiregional Firms and Region Switching in the US Manufacturing Sector ${ }^{\star}$
}

by

\author{
Antoine Gervais \\ University of Notre Dame
}

\begin{abstract}
CES 15-22 August, 2015
The research program of the Center for Economic Studies (CES) produces a wide range of economic analyses to improve the statistical programs of the U.S. Census Bureau. Many of these analyses take the form of CES research papers. The papers have not undergone the review accorded Census Bureau publications and no endorsement should be inferred. Any opinions and conclusions expressed herein are those of the author(s) and do not necessarily represent the views of the U.S. Census Bureau. All results have been reviewed to ensure that no confidential information is disclosed. Republication in whole or part must be cleared with the authors.

To obtain information about the series, see www.census.gov/ces or contact Fariha Kamal, Editor, Discussion Papers, U.S. Census Bureau, Center for Economic Studies 2K132B, 4600 Silver Hill Road, Washington, DC 20233, CES.Papers.List@ census.gov.
\end{abstract}




\begin{abstract}
This paper uses data on US manufacturing firms to study a new extensive margin, the reallocation of resources that takes place within surviving firms as they open and close establishments in different regions. To motivate the empirical analysis, I extend existing models of industry dynamics to include production-location decisions within firms. The empirical results provide support for the mechanisms emphasized by the theoretical model. In the data, only about 3 percent of firms make the same product in more than one region, but these multiregional firms are more productive on average compared to single-region firms, and they account for about two-thirds of output. The results also show that "region-switching" is pervasive among multiregional firms, is correlated with changes in firm characteristics, and leads to a more efficient allocation of resources within firms.
\end{abstract}

Keyword: Multiregional firms, firm heterogeneity, industry dynamics, monopolistic competition, proximity-concentration tradeoff.

\title{
JEL Classification: L2
}

\footnotetext{
* Department of Economics, University of Notre Dame, Notre Dame, IN 46556, USA (email: agervais@nd.edu). I thank Jeff Bergstrand, Dave Donaldson, Aaron Flaaen, Fabio Ghironi, J. Bradford Jensen, Fariha Kamal, James Markusen, and Nina Pavcnik as well as participants at various conferences for useful comments on earlier versions of this paper. All remaining errors are my own. Special thanks to Frank Limehouse for timely help with disclosure. The empirical research in this article was conducted at the Federal Reserve Bank of Chicago Census Regional Data Center. Any opinions and conclusions expressed herein are my own and do not necessarily represent the views of the US Census Bureau. All results have been reviewed to ensure that no confidential information is disclosed.
} 


\section{Introduction}

Empirical research using producer-level microdata demonstrates the importance of withinindustry reassignment of resources across producers in explaining industry performance (e.g., Baily et al. (1992); Dunne et al. (1989); Bartelsman and Doms (2000); Foster et al. (2001); Rossi-Hansberg and Wright (2007); and Foster et al. (2008)). So far, studies of industry dynamics have focused almost exclusively on the role of resource reallocation across producers, that is, whether new entrants are more productive than exiting producers in the same industry. In this paper, I explore the contribution of a new extensive margin of adjustment, the spatial reallocation of resources that takes place within surviving firms as they open and close establishments in different regions of the United States (US). The empirical results suggest that "region switching" is an important internal adjustment margin that firms employ to reallocate resources to their best use.

To study the complex firm dynamics underlying changes in aggregate output and employment, I construct a new longitudinal dataset from the US Census of Manufactures. The Census of Manufactures collects information on the universe of manufacturing establishments located in the US. Each establishment is associated with a firm identifier which makes it possible to track the ownership structure of firms in any given year, as well as changes over time. For each firm-year in the data, I observe the geographic location of its establishments, as well as the distribution of input usage and output production across these establishments. This unique dataset enables me to provide a rich description of industry dynamics that distinguishes between within- and across-firm adjustments.

My analysis of the data provides new insights into the spatial distribution of firm's output and the role of region switching in explaining changes in industry aggregates. First, only about 3 percent of US manufacturing firms produce the same six-digit North American Industrial Classification System (NAICS) product in more than one region, but these multiregional firms account for a disproportionate share of economic activity: more than two-thirds of manufac- 
turing output and about half of employment. Second, region switching by multiregional firms is an important component of the "creative destruction" process that underlies economic growth (Schumpeter (1942)). Over the five-year period from 2002 to 2007, manufacturing output increased by about 6 percent per year on average. Surviving multiregional firms account for about 75 percent of that growth. On net, region adding and dropping generate about 1 percent annual growth, whereas incumbent region expansion and contraction lead to an additional 3.5 percent net increase in output. These results suggests that understanding how firms evolve over time is critical in explaining industry dynamics.

Existing models of industry dynamics typically feature productivity-heterogenous firms that produce in a single location (e.g., Jovanovic (1982); Hopenhayn (1992); Ericson and Pakes (1995); Melitz (2003); Bernard et al. (2010); and Bernard et al. (2011)). In that case, firm and region exit are equivalent. To study the determinants of within-firm region switching, I extend current theories to allow firms to serve consumers through interregional sales and interregional investment, i.e., by opening a local establishment. I model firms' region entry and production-location decisions using the proximity-concentration tradeoff framework developed in Helpman et al. (2004). Compared to interregional sales, interregional investment leads to higher fixed costs but lower marginal costs. In equilibrium, only the most productive firms choose to serve consumers through local presence and become multiregional firms.

In the data, I find that about 70 percent of surviving multiregional firms either entered or exited a region over the five-year period from 2002 to 2007. Current models of productionlocation decisions that study firm behavior in a "static" context (e.g., Brainard (1997); Helpman et al. (2004); and Ramondo and Rodríguez-Clare (2013)) are inconsistent with that finding because, in those models, firm productivity and market characteristics are constant over time such that the optimal spatial distribution of production remains the same over the lifetime of firms. To generate equilibrium region switching within firms, I extend existing models in two ways. First, I assume that profitability varies across firms because of changes in productivity and within firms across regions because of changes in consumers' valuation of 
a firm's product. Second, I assume that firm productivity and firm-region demand evolve stochastically over time. Because my model distinguishes between firm-level and firm-region level shocks, it is consistent with the fact that firms sometimes enter and exit regions during the same period.

My theoretical framework highlights the role of firm productivity in explaining differences in outcome across firms. In equilibrium, the most productive firms generate more revenue per region on average and, as a result, are more likely to serve consumers by opening local establishments. The empirical results support the predictions of the theoretical model. In the data, I find that measures of productivity are higher on average for multiregional firms compared to single-region firms in the same industry. These differences persist even when comparing revenue per region. Multiregional firms sell more on average in a region compared to single-region firms located in that region.

My empirical analysis shows region switching leads to a more efficient allocation of resources within firms through the mechanisms emphasized by the theoretical model. First, in the data there is a positive correlation between changes in firm-level indicators of performance and changes in the number of regions in which a firm has a production facility. This finding is consistent with the model's prediction that a positive shock to firm productivity will, all else equal, raise profits in all regions and increase the firm's geographic scope. Second, in the data, region entry is positively correlated with measures of firm productivity and region exit is negatively correlated with relative region size within the firm. In the model, the decision to enter or exit a region depends on the interaction between firm-level changes in productivity and firm-region level changes in demand. Because of serial correlation in shocks, firms with high productivity are more likely to receive positive productivity shocks and open establishments in new regions. At the same time, firms are more likely to close their production facilities in their least profitable regions, i.e., those where they face relatively low demand. 
This paper is related to an emerging literature that studies the contribution of the withinfirm extensive products margin in explaining firm outcomes (e.g., Goldberg et al. (2010); Iacovone and Javorcik (2010); Qiu and Zhou (2013); Mayer et al. (2014); and Timoshenko (2014)). In particular, Bernard et al. (2010) and Bernard et al. (2011) introduce multiproduct firms into a model of industry dynamics and study the frequency and determinants of product switching by US manufacturing firms. Because the current paper focuses on the

firm's production-location decision and region switching, the studies are complementary. Together, they bring to the fore the importance of within-firm adjustments in explaining industry dynamics.

The remainder of the paper is composed of four sections. In section 2 , I develop a theoretical model of industry dynamics that features firm heterogeneity and the proximity-concentration tradeoff. In section 3, I describe the data and document the prevalence of multiregional firms. In section 4, I present the main empirical analysis and, in section 5, I provide some concluding comments.

\section{Theoretical Framework}

In this section, I develop a model of industry dynamics that includes endogenous productionlocation decisions within firms. The theoretical framework is an extension of standard models of industry dynamics (e.g., Jovanovic (1982); Hopenhayn (1992); Ericson and Pakes (1995); and Melitz (2003)) that allows for multiregional firms and region switching. It is also an extension of current models of production-location decisions (e.g., Brainard (1997); Helpman et al. (2004); and Ramondo and Rodríguez-Clare (2013)) in which firm characteristics evolve stochastically over time. By combining elements from these two strands of the literature, the theoretical model rationalizes variation in the spatial distribution of production both across firms and within firms over time. 
Because my empirical analysis is limited to the domestic activities of US manufacturing firms, the theoretical framework models bilateral sales and investment flows between regions of a closed economy. However, the leap from interregional sales and investment to international trade and foreign direct investment is small, such that the theoretical model would remain valid in an international context and could be used to study multinational enterprises.

\subsection{Demand}

I begin by characterizing the behavior of consumers. The economy is comprised of $i=$ $1,2, \ldots, N$ identical regions. In each region, there is a mass $L$ of consumers each endowed with one unit of labor. Preferences of the representative consumer in region $i$ are a constant elasticity of substitution (CES) function of the consumption of a continuum of products

$$
U_{i}=\left[\int_{x \in X_{i}}\left(\lambda_{i}(x) q_{i}(x)\right)^{\frac{\varepsilon-1}{\varepsilon}}\right]^{\frac{\varepsilon}{\varepsilon-1}}
$$

where $x$ indexes differentiated varieties, $X_{i}$ denotes the endogenous set of varieties available for consumption in region $i, q_{i}(x)$ is the quantity consumed, and $\lambda_{i}(x)$ is a demand parameter. Because relative demand is increasing in the demand parameter, a natural interpretation is product quality but it also captures every other characteristic of a variety that influences consumer's demand. ${ }^{1}$

The representative consumer maximizes utility subject to his budget constraint. The optimal demand function for a differentiated variety $x$ is given by

$$
q_{i}(x)=R_{i} P_{i}^{\varepsilon-1} \lambda_{i}(x)^{\varepsilon-1} p_{i}(x)^{-\varepsilon}, \quad \text { where } \quad P_{i}=\left[\int_{x \in X_{i}}\left(\frac{p_{i}(x)}{\lambda_{i}(x)}\right)^{1-\varepsilon} d x\right]^{\frac{1}{1-\varepsilon}}
$$

\footnotetext{
${ }^{1}$ This functional form is standard in the empirical literature on international trade and product quality (e.g., Gervais (2013); Hallak and Sivadasan (2013); Johnson (2012)); and Kugler and Verhoogen (2012)), and has been used in multi-product firms settings (e.g., Bernard et al. (2010); and Bernard et al. (2011)).
} 
denotes the ideal price index, $p_{i}(x)$ is the price of variety $x$ in region $i$ and $R$ denotes total expenditure in each region. The parameter $\varepsilon>1$ governs the price elasticity of demand, which is constant across firms. Equation (2) makes clear that, all else equal, the demand for a given variety $x$ will be higher in regions where $\lambda_{i}(x)$ is higher. As a result, the model features within-firm variation in sales across regions, despite the fact that regions are of the same size.

\subsection{Production costs}

I now turn to the production side of the economy. In each region, there is an endogenous measure $M$ of firms that produce differentiated goods. To enter the industry a firm must pay a fixed cost, $f_{E}$, to develop a "blueprint" for a differentiated variety. The entry cost generates firm-level returns to scale and implies that each firm will choose to produce a unique variety. Upon entry the firm draws its initial productivity, $\varphi \in\left[\varphi_{L}, \varphi_{H}\right] \subseteq \mathbb{R}^{+}$, and vector of demand shocks, $\boldsymbol{\Lambda} \equiv\left[\lambda_{i}\right]_{N \times 1}$, with $\lambda_{i} \in\left[\lambda_{L}, \lambda_{H}\right] \subseteq \mathbb{R}^{+}$from continuous distribution functions with cumulative distribution $G_{E}(\varphi)$, and $\mathscr{H}_{E}(\boldsymbol{\Lambda})$, respectively. These distributions are the same in all regions.

Productivity is firm-specific, reflecting variation in ability across firms, whereas the demand parameters are firm-region specific and reflect within-firm variation in demand across regions. $^{2}$ Since productivity is common across regions, a firm's profitability is correlated across regions. To make use of the law of large numbers, I assume that firm productivity and demand shocks are independent of one another and independently distributed across firms, and that demand shocks are independently distributed across regions within the firm. This implies that $\mathscr{H}_{E}(\boldsymbol{\Lambda})=\prod_{N} H_{E}(\lambda)$, where $H_{E}(\lambda)$ denotes the cumulative distribution of initial demand shocks within each region.

Firms can produce differentiated varieties using only one input, labor. A firm with productivity $\varphi$ that chooses to sell locally, i.e., in the region where its headquarters is located,

\footnotetext{
${ }^{2}$ With CES demand and monopolistic competition, changes in productivity and tastes have equivalent impacts on firm profitability. Allowing for variation in firm productivity across markets would not affect the main results. The important point is that there is a firm-level component and a firm-market component to stochastic shocks.
} 
faces a constant marginal cost of $w / \varphi$, where $w$ is the common wage rate (hereafter normalized to 1 without loss of generality) and $1 / \varphi$ is the number of workers required to produce one unit of output. ${ }^{3}$ For interregional sales, the firm faces two additional costs. A fixed costs equal to $f_{X}$ per region and per-unit transport $\operatorname{costs} \tau$. The unit costs have the typical "iceberg" form such that if $\tau>1$ units are shipped from one region to another, only one unit arrives. If the firm chooses instead to open a new establishment to serve local demand, it incurs fixed $\operatorname{costs} f_{I}$ per region. The fixed costs $f_{X}$ reflects the costs of developing a distribution network in the region while the fixed costs $f_{I}$ captures these costs and any additional costs associated with setting up a production facility. The difference between $f_{I}$ and $f_{X}$ is therefore a measure of establishment-level returns to scale.

\subsection{Equilibrium production decisions}

In this section, I combine the demand and supply sides of the model to derive the firm's optimal behavior conditional on a vector of characteristics $(\varphi, \boldsymbol{\Lambda})$. In the model, firms choose the set of regions to serve and, for each region, the optimal price and mode of entry. I examine each decision in turn beginning with the pricing decision.

In each region, there is monopolistic competition in the final output market. Because regions are segmented markets, firms maximize profits by choosing the price in each region separately. In equilibrium, prices are a constant mark-up over marginal costs

$$
p_{D}(\varphi)=p_{I}(\varphi)=\frac{1}{\rho \varphi}, \quad \text { and } \quad p_{X}(\varphi)=\tau p_{D}(\varphi)
$$

where $p_{D}, p_{X}$ and $p_{I}$ denote local, interregional sales, and interregional investment prices respectively, and $1 / \rho=\varepsilon /(\varepsilon-1)>1$ is the markup. CES preferences imply that prices are inversely related to firm productivity $\varphi$ but independent of the demand parameter $\lambda$. Changes in the demand parameter (across-firms and within-firm across regions) will only show up

\footnotetext{
${ }^{3}$ To simplify the analysis, I assume there is no fixed production costs in the "domestic" region. This rules out cases where a firm is not profitable in its domestic market but makes positive profits in other regions.
} 
in the quantity demanded (see equation (2)). Because firms charge a constant markup over costs, domestic and interregional investment prices are equal while interregional sales prices are higher, reflecting the increase in marginal production costs.

I now describe the region entry decision. Operating profits from serving the local region for a firm with productivity $\varphi$ and local demand shock $\lambda_{i}$ are

$$
\pi_{D}^{i}(\varphi, \boldsymbol{\Lambda})=\varepsilon^{-1} A\left(\varphi \lambda_{i}\right)^{\varepsilon-1}, \quad \text { where } \quad A=R(\rho P)^{\varepsilon-1}
$$

is a constant. ${ }^{4}$ Equations (4) shows that, because of CES preferences, productivity and demand shocks have equivalent impacts on firm profitability. It also shows that firms always make positive profits when selling in their local regions because they face only marginal costs. This implies that all $M$ firms with headquarters located in a given region will produce and sell in that region. However, because sales to other regions imply fixed costs, only a fraction of firms will serve more than one region. The additional profits from interregional sales and investment for a firm with headquarter in region $i$ selling to region $j \neq i$ consumers are, respectively,

$$
\pi_{X}^{j}(\varphi, \Lambda)=\frac{A}{\varepsilon}\left(\frac{\varphi \lambda_{j}}{\tau}\right)^{\varepsilon-1}-f_{X} \quad \text { and } \quad \pi_{I}^{j}(\varphi, \Lambda)=\frac{A}{\varepsilon}\left(\varphi \lambda_{j}\right)^{\varepsilon-1}-f_{I}
$$

where $\lambda_{j}$ denotes the firm's demand shock in region $j$. In equilibrium, firms will sell in every region where they can generate positive profits from interregional sales or investment.

I conclude the description of firms' behavior by studying the production-location decision. Profit maximizing firms will never ship output to a region where they operate a production facility. In the model, the optimal choice of mode of entry depends on a proximityconcentration tradeoff; relative to interregional investment, interregional sales imply higher marginal costs but lower fixed costs. Because the profit functions are monotonically increasing

\footnotetext{
${ }^{4}$ Because of the assumptions on the distribution of shocks and region symmetry, the law of large number implies that the price index $P$ and, as a result, the demand parameter $A$ is constant across regions.
} 
in productivity $(\varphi)$ and demand shocks $(\lambda)$, there exists a conditional productivity threshold $\varphi_{X}(\lambda): \pi_{X}\left[\varphi_{X}(\lambda), \lambda\right]=0$, such that firms will make profitable interregional sales in region $j$ only if $\varphi \geq \varphi_{X}\left(\lambda_{j}\right)$, where $\lambda_{j}$ denotes the firm's demand shock in region $j$. Similarly, there exists a conditional productivity threshold $\varphi_{I}(\lambda): \pi_{I}\left[\varphi_{I}(\lambda), \lambda\right]=0$, such that firms will make profitable interregional investment sales in region $j$ only if $\varphi \geq \varphi_{I}\left(\lambda_{j}\right) .^{5}$

Firms will produce for interregional sales only if profits from those sales are positive and smaller than profits from interregional investment sales. From the definitions of profits in (5), the conditional productivity thresholds above which firms engage in interregional sales, $\varphi_{X}(\lambda)$, and prefer interregional investment over interregional sales, $\varphi_{I}(\lambda)$, are

$$
\varphi_{X}(\lambda)=\left(\frac{\varepsilon f_{X}}{A}\right)^{\frac{1}{\varepsilon-1}} \frac{\tau}{\lambda}, \quad \text { and } \quad \varphi_{I}(\lambda)=\left[\frac{f_{I}-f_{X}}{f_{X}\left(\tau^{\varepsilon-1}-1\right)}\right]^{\frac{1}{\varepsilon-1}} \varphi_{X}(\lambda)
$$

respectively. Bernard et al. (2009) and Helpman et al. (2004) provide empirical evidence that suggests multinational firms are more productive compared to exporters. Similarly, as reported in section 4 below, I find that multiregional firms are more productive on average compared to firms that produce in only one region. Therefore, as in Helpman et al. (2004), I assume that

$$
f_{I}>\tau^{\varepsilon-1} f_{X}
$$

This condition requires that the fixed production costs associated with interregional investment are greater than a product of the costs associated with interregional sales. When this condition holds, the conditional productivity threshold for interregional investment is greater than the threshold for interregional sales (i.e., $\left.\varphi_{I}(\lambda)>\varphi_{X}(\lambda), \forall \lambda \in\left[\lambda_{L}, \lambda_{H}\right]\right){ }^{6}$

The sorting of firms across type in the representative region of the economy is depicted in Figure 1 in $(\lambda, \varphi)$-space. Because there is no fixed production costs in the domestic region,

\footnotetext{
${ }^{5}$ The costs of shipping between any two regions is the same for all regions. This implies export profits are independent of the location of production such that there is no "export-platform" motive for opening an establishment, and that the distribution of the firm's production for interregional sales across establishments is indeterminate in this model.

${ }^{6}$ Because demand shocks are bounded above at $\lambda_{H}$, it is possible to define the minimum productivity required for profitable interregional sales, $\varphi_{X}^{*}=\varphi_{X}\left(\lambda_{H}\right)$, and investment is $\varphi_{I}^{*}=\varphi_{I}\left(\lambda_{H}\right)$.
} 
all firms will produce and sell in their local region. The set of active firms is represented in the figure by the area with vertices at $\left(\lambda_{L}, \varphi_{L}\right),\left(\lambda_{L}, \varphi_{H}\right),\left(\lambda_{H}, \varphi_{H}\right)$, and $\left(\lambda_{H}, \varphi_{L}\right)$. The fixed costs associated with interregional sales and investment imply that only a fraction of firms will engage in those activities. The figure represents the conditional productivity threshold functions for interregional sales and investment, $\varphi_{X}(\lambda)$ and $\varphi_{I}(\lambda)$, defined in equation (6). Firms with headquarters located outside the region will ship output to the region if their productivity-demand shock pair lies in the quarter-ring area of the graph, or open a local establishment if their productivity-demand shock pair lies in the quarter-moon region in the North-East part of the graph.

\section{[FIGURE 1: HERE]}

A key distinction between my model and Helpman et al. (2004) is that profitability is a function of firm-productivity and firm-region demand. This has two important implications. First, the sorting of firms across type (i.e., single- vs. multi-region firms) depends on the interaction between these two sources of heterogeneity. For example, as illustrated in Figure 1, a low productivity firm may open an establishment in a high demand region. Second, because demand shocks are firm-region specific, a firm's optimal mode of entry will vary across identical regions. In equilibrium, a firm could serve consumers in a subset of regions through interregional sales, open affiliates in another subset of regions, and decide not to enter the remaining regions. Another important difference between my model and Helpman et al. (2004) is that firm productivity and demand shocks are stochastic. As described in details in the next section, this implies that the set of regions in which a particular firm is active will change over time.

\subsection{Stationary equilibrium}

In this section, I describe the main features of the equilibrium. The discussion focuses on

firm-level characteristics. The Technical Appendix at the end of the paper completes the 
characterization of the equilibrium by providing solutions for the aggregate variables of the model (e.g., the stationary distribution of firms over productivity and taste parameters).

At the beginning of each period, each firm draws a new productivity and demand vector. Firm productivity and firm-region demand shocks evolve stochastically over time. To capture the well documented persistence of firm output observed in the data (e.g., Foster et al. (2008)), I allow for positive serial correlation in both productivity and demand. The transition matrices are represented by Markov processes independent across firms and regions with conditional distributions $G_{C}\left(\varphi^{\prime} \mid \varphi\right)$ with $\partial G_{C}\left(\varphi^{\prime} \mid \varphi\right) / \partial \varphi<0$ and $H_{C}\left(\lambda^{\prime} \mid \lambda\right)$ with $\partial H_{C}\left(\lambda^{\prime} \mid \lambda\right) / \partial \lambda<0$. After observing its vector of shocks, the firm chooses the set of regions to serve, the location of its establishments, and the price to charge in each region.

As in Melitz (2003) and Bernard et al. (2010), I focus on a stationary equilibrium in which aggregate variables remain constant over time. The aggregate state of the economy is fully characterized by the number of firms with headquarters in each market, $M$, and the distributions of productivity and demand shocks across these firms. Because there is a continuum of firms operating in each region and the distribution of entering firms over initial productivity and tastes shocks is the same in every regions and periods, the equilibrium distribution of firms over states is governed by the initial distributions of productivity and demand shocks $\left(G_{E}(\varphi), H_{E}(\lambda)\right)$, the Markov processes $\left(G_{C}\left(\varphi^{\prime} \mid \varphi\right), H_{C}\left(\lambda^{\prime} \mid \lambda\right)\right)$, and the exit shock $(\delta) \cdot{ }^{7}$ As a result, there exists a stationary distribution of firms over states (see Technical Appendix for additional details).

In each period, firm profit depends on the firm's productivity and demand shocks as follows

$$
\pi_{i}(\varphi, \boldsymbol{\Lambda})=\pi_{D}\left(\varphi, \lambda_{i}\right)+\sum_{j \neq i}\left[I_{X}^{j}\left(\varphi, \lambda_{j}\right) \pi_{X}^{j}\left(\varphi, \lambda_{j}\right)+I_{I}^{j}\left(\varphi, \lambda_{j}\right) \pi_{I}^{j}\left(\varphi, \lambda_{j}\right)\right]
$$

where region-level profit functions are defined in equations (4) and $(5), I_{X}^{j}(\varphi, \lambda)$ is an indicator variable equal to 1 if a region- $i$ firm ships output to region $j$ (i.e., $\left.\varphi \in\left[\varphi_{X}(\lambda), \varphi_{I}(\lambda)\right]\right)$ and 0

\footnotetext{
${ }^{7}$ See Hopenhayn (1992) for a discussion of the technical problems associated with dealing with continuums of random variables.
} 
otherwise, and $I_{I}^{j}(\varphi, \lambda)$ is an indicator variable equal to 1 if the firm opens an establishment in region $j$ (i.e., $\varphi>\varphi_{I}(\lambda)$ ) and 0 otherwise. ${ }^{8}$ A firm faces two sources of uncertainty, the sequence of productivity and demand shocks it will receive and the probability $\delta$ of a bad shock that would force it to exit. The present discounted value of an incumbent firm is a function of its current state and is defined in recursive form as

$$
v(\varphi, \mathbf{\Lambda})=\pi(\varphi, \mathbf{\Lambda})+(1-\delta) \int_{\varphi} \int_{\mathbf{\Lambda}} v\left(\varphi^{\prime}, \boldsymbol{\Lambda}^{\prime}\right) d G_{C}\left(\varphi^{\prime} \mid \varphi\right) d \mathscr{H}_{C}\left(\mathbf{\Lambda}^{\prime} \mid \mathbf{\Lambda}\right)
$$

where a prime indicates next period values. In the free entry equilibrium, the expected value of entry $(\bar{v})$ is equal to the sunk entry costs which requires that

$$
\bar{v} \equiv \int_{\varphi} \int_{\boldsymbol{\Lambda}} \tilde{v}(\varphi, \boldsymbol{\Lambda}) d G_{E}(\varphi) d \mathscr{H}_{E}(\boldsymbol{\Lambda})=f_{E}
$$

where $\tilde{v}(\varphi, \boldsymbol{\Lambda})$ is the solution to the Bellman equation (9).

I use the theoretical model's predictions to organize the empirical analysis and rationalize the findings that emerge from it. The model predicts sorting of firms across type such that multiregional firms are larger and more productive on average. The stationary equilibrium of the model features entry and exit of firms in the industry because of the random shock $\delta$. Because productivity and demand shocks are stochastic, the equilibrium also features region switching by incumbent firms. The theoretical model predicts that firms receiving positive productivity shocks are more likely to enter new regions. At the same time, firms that receive negative region-level demand shocks are more likely to exit from those regions. Together, these results imply that the model is consistent with simultaneous region entry and exit within firms.

\footnotetext{
${ }^{8} \mathrm{I}$ assume closing an establishment provides a present discounted value of zero so that a firm will close an establishment the first time its shocks result in negative establishment-level profits. Similarly, a firm will stop selling to a region if profits from interregional sales are negative.
} 


\section{Data and Measurement}

I study region switching using a new longitudinal dataset constructed from the US Census of Manufactures (CM). The CM is a component of the US Census Bureau's Economic Census which is conducted every five years (in years ending in 2 and 7). For the analysis, I use information from the two most recent years available, 2002 and $2007 .{ }^{9}$ The unit of observation in the CM is the establishment, defined as a single physical location where output is produced. ${ }^{10}$ The CM covers the universe of manufacturing establishments with one or more paid employees and collects information on physical location, principal industry, use of inputs, input costs, and value of shipment. The information is obtained from questionnaires firms are required to fill out under Title 13 of the United States Code.

In the data, I define an industry as a six-digit NAICS category. As explained in United States Census Bureau (2007), the NAICS identifies 472 manufacturing industries across 86 four-digit industry groups. To get a sense of the level of details, consider the "Semiconductor and Other Electronic Component Manufacturing" industry group (NAICS 3344). The industry comprises nine six-digits NAICS industries ranging from "Electron Tube Manufacturing" (NAICS 334411) to "Printed Circuit Assembly" (NAICS 334418). Output in those industries vary both in terms of the inputs and processes required to produce them, and in terms of their potential end use.

The CM associates a company identifier with each establishment-year observation which makes it possible to track the ownership structure of companies in any given year, as well as changes over time. ${ }^{11}$ For the analysis, I define a firm as a collection of establishments with the

\footnotetext{
${ }^{9}$ I use only two Censuses to minimize the impact of changes in the product classification definition and industry characteristics. Results are similar when using the 1997 and 2002 Censuses or a longer panel including the 1997, 2002, and 2007 Censuses.

${ }^{10}$ Companies engaged in different production activities at one location are requested to submit separate reports to the US Census if the activities are substantial in size. When this condition is not met, activities at the same location are grouped together as a single establishment and the entire establishment is classified on the basis of its primary activity.

${ }^{11}$ The Economic Census uses Employer Identification Number also known as a Federal Tax Identification Number to identify a business entity (e.g., Jarmin and Miranda (2002); and United States Census Bureau
} 
same six-digit NAICS principal industry and owned by the same company. ${ }^{12}$ This focuses the analysis on the impact of market-seeking behavior, as emphasized in the theoretical model. In practice, this definition implies that large companies will be broken down into multiple firms according to the six-digit NAICS industry classification of their establishments. Henceforth, "firm" refers to the empirical definition.

To characterize the geographical dispersion of firms' production activities, I define regions using the Bureau of Economic Analysis' Economic Areas (EAs). ${ }^{13}$ EAs are defined as metropolitan areas and their adjoining counties, where the adjoining counties are determined by commuting patterns and other indicators of interaction (see Johnson and Kort (2004) for additional details). Compared to states, counties, or zip code, EAs represent geographic areas that are consistent with the notion of a regional market. The 183 EAs are mutually exclusive and exhaustive of the land area of the United States.

The CM provides detailed, establishment-level data on the location of production and the destination of output. For each establishment, the CM records the total value of shipment and the value of exports to other countries. Therefore, it is possible to construct firm-region level measure of revenue generated from sales to US consumers. However, it is not possible to construct firm-level measures of interregional trade flows because the CM does not collect information of domestic sales destinations. ${ }^{14}$ In the empirical analysis, I focus on interregional investment and MRF region switching and, following the model, control for the impact of differences in trade costs across industries using industry-level fixed effects.

For convenience, I will refer to firms that produce in multiple regions as "MRF," for Multi-Region Firms, and firms that produce in a single region as "SRF," for Single-Region

(2007)). As explained in Internal Revenue Service (2014), each business should have a unique EIN and does not need a new EIN if it changes location, or open and close establishments (including mergers and acquisitions).

${ }^{12}$ According to the US Census 2007 Survey of Business Owners, only about 1.3 percent of manufacturing establishments are franchises and these establishments account only for about 0.2 percent of total manufacturing output.

${ }^{13}$ As explained further in the robustness section below, the results are robust to changes in the definition of geographic markets.

${ }^{14}$ The US Census Bureau's Commodity Flow Survey does not provide a full list of sales destinations for the firms it surveys. Therefore, that information cannot be used to test the predictions of the model. 
Firms. Table 1 documents the relative importance of MRF for census year 2007; results are almost identical for 2002. The table presents the share of manufacturing firms that operate in more than one region, the share of output and employment these firms account for, as well as the average number of regions per MRF. As indicated in the table, while only about 3 percent of manufacturing firms are MRF, these firms account for about two-thirds of sales and close to half of employment. The last row shows that the average MRF produces the same six-digit NAICS output in about 3.6 regions.

\section{[TABLE 1: HERE]}

\section{Empirical Evidence}

In this section, I confront the theoretical model's predictions with the data. Given that a large amount of research examines firm creation and destruction, the analysis focuses on the region switching behavior of surviving MRF highlighted by the theoretical model. I report empirical evidence at three levels of aggregation. First, I explore the role of region switching in explaining aggregate industry dynamics in the manufacturing sector. Second, I document patterns of region switching at the firm-level. Finally, I examine patterns of entry and exit within surviving multiregional firms. Overall, the empirical results provide support to the main mechanisms emphasized in the theoretical model. Formal derivation of the implications of the model are available in the Technical Appendix at the end of the paper.

\subsection{Manufacturing sector}

A large empirical literature on industry dynamics demonstrates that the reallocation of output and inputs across producers plays a key role in explaining gross output and employment flows in the US manufacturing sector (e.g. Dunne et al. (1989) and Foster et al. (2001)). In contrast, my theoretical model emphasizes the within-firm reallocation of resources across 
regions. To evaluate the relative importance of these two margins, I decompose net changes in aggregate output and employment into across- and within-firm components.

Given information on the population of firms in each of two census years, $t$ and $t+5$, it is possible to classify each firm according to whether a firm first appears in period $t+5$ (a birth), appears in period $t$ but not $t+5$ (a death), or continues operation from period $t$ to $t+5$. It is also possible using information on the regions in which firms operate in each of the two periods to classify them according to whether they have the same unique region in both periods $(\mathrm{SRF})$ or they operate in multiple regions in period $t$ or $t+5(\mathrm{MRF})$. Output (or employment) for each group can be defined as

$$
\begin{aligned}
& B_{t+5}=\text { the value of output (or employment) in period } t+5 \text { in all firms } \\
& \text { that first appear in period } t+5 \text {; } \\
& A_{t+5}^{M R F}=\text { the value of output (or employment) in period } t+5 \text { in all regions } \\
& \text { added in period } t+5 \text { by surviving MRF; } \\
& E_{t}^{k}, E_{t+5}^{k}=\text { the value of output (or employment) in period } t \text { and } t+5 \text {, } \\
& C_{t}^{k}, C_{t+5}^{k}=\text { the value of output (or employment) in period } t \text { and } t+5 \text {, }
\end{aligned}
$$

Using those definitions, the total output (or employment) in each of the two periods, $Y_{t}$ and $Y_{t+5}$, can be expressed as

$$
\begin{gathered}
Y_{t}=E_{t}^{M R F}+C_{t}^{M R F}+T_{t}^{M R F}+E_{t}^{S R F}+C_{t}^{S R F}+D_{t}, \\
Y_{t+5}=B_{t+5}+A_{t+5}^{M R F}+E_{t+5}^{M R F}+C_{t+5}^{M R F}+E_{t+5}^{S R F}+C_{t+5}^{S R F} .
\end{gathered}
$$


The annualized changes in output (or employment) over the five-year interval 2002-2007 is given by

$$
\Delta Y_{t, t+5}=B_{t+5}+A_{t+5}^{M R F}+\Delta E_{t, t+5}^{M R F}+\Delta C_{t, t+5}^{M R F}-T_{t+5}^{M R F}+\Delta E_{t, t+5}^{S R F}+\Delta C_{t, t+5}^{S R F}-D_{t} .
$$

Table 2 presents estimates of the gross expansion and contraction rates of output and employment over the 2002-07 period as a proportion of base and end-year average, $\bar{Y}=$ $\left(Y_{t}+Y_{t+5}\right) / 2 .{ }^{15}$ The first line of Table 2 reports the average percentage change in output (or employment) per year between Census years. The remaining lines divide this net change into the eight gross flow components as shown in equation (13). By definition, these components sum to the growth rate of manufacturing output (or employment) reported in the first line.

\section{[TABLE 2: HERE]}

As shown in the second column of Table 2, aggregate manufacturing output in the US increased by 6 percent per year on average between 2002 and 2007. In line with previous empirical studies of industry dynamics, the results show that producer entry (i.e., the sum of firm birth and surviving MRF region entry) and exit (i.e., the sum of firm death and surviving MRF region exit) explain the majority of output and employment churning. An important new insight of these results, however, is that region entry and exit by surviving MRF accounts for about a third of the extensive margin adjustment. ${ }^{16}$ Given the short period of time covered by the sample, this should be viewed as a conservative estimate because new establishments are likely to grow in importance as they age. The results in Table 2 also reveal these surviving MRF are the primary source of output growth in the manufacturing sector. On net, these firms generate 4.5 percent growth per year on average, or about 75 percent of total growth over the 2002-2007 period. By contrast, firm birth and death increase output by

\footnotetext{
${ }^{15}$ As explained in Foster et al. (2001), the advantage of this growth rate measure is that it is symmetric for positive and negative changes which allows for an integrated treatment of entering and exiting establishments.

${ }^{16}$ From the results reported in the first column of Table 2, dividing the sum of surviving MR entry and exit $(3.15+2.23=5.35)$ by the sum of firm birth, surviving MRF region entry and exit, and firm death $(4.44++3.15+2.23+4.11)$ yields 37.62 percent.
} 
about a third of a percent and the expansion and contraction of surviving SRF lead to a net growth of only about 1.3 percent per year.

The second column of Table 2 reports the breakdown of net employment change using the decomposition shown in equation (13). The results show that gross changes in employment are larger than the associated net changes; in the words of Davis and Haltiwanger (1992), there is "excess reallocation." Together, the output and employment results reported in Table 2 imply a substantial increase in (labor) productivity in the manufacturing sector. Manufacturing output grows at a rate of about 6 percent per year on average while employment shrinks at a rate of about 2 percent per year. Therefore, consistent with the theoretical model, these results suggest that firms expand output in productive regions and exit relatively unproductive ones. The remainder of the empirical analysis provides a formal assessment of this conjecture.

\subsection{Region switching}

In the model, high productivity firms sell more output per region on average and are more likely to serve demand through interregional investment. As a result, MRF should be larger and more productive on average compared to SRF. To test those predictions, I compare the characteristics of SRF and MRF using OLS regressions of the natural log of firm characteristics on an indicator variable, ID ${ }^{M R F}$, equal to one if the firm operates in multiple regions and zero otherwise

$$
\ln Z_{f}=\beta_{s}+\beta_{m} \mathrm{ID}_{f}^{M R F}+\mu_{f}
$$

where $f$ and $s$ index, respectively, firm and industry, and $\mu_{f}$ is a residual term. The variable $Z_{f}$ is, in turn, firm-level output, employment, labor productivity, and TFP. ${ }^{17}$ The regressions include a full set of industry dummy variables $\left(\beta_{s}\right)$ such that the results are not driven by differences in industry characteristics (e.g., trade costs).

\footnotetext{
${ }^{17}$ I compute measures of performance for each establishment separately. Output is defined as the primary product value of shipment for domestic sales. Productivity is defined as sales minus costs of material over hours worked. I compute TFP using an index method that accounts for variation in capital, energy, labor, and materials across establishments (see Foster et al. (2008) for details). For MRF, I obtain firm-level and firm-region level measures by computing revenue weighted averages across establishments.
} 
I report the estimation results in Panel A of Table 3 for year 2007; results are similar for 2002. Consistent with the model's prediction, the results show that MRF are larger and more productive on average compared to SRF in the same industry. Those differences are statistically significant at conventional levels. As reported in Table 3, the output and employment reported by MRF are more than twice as large on average compared to corresponding values reported by SRF in the same industry. As indicated in the table, MRF also have higher labor productivity and TFP than SRF. The difference in measured TFP across firm-type is small relative to the difference in productivity, perhaps due to the difficulties of measuring TFP in firms with multiple establishments.

\section{[TABLE 3: HERE]}

In the theoretical model, MRF are more productive on average. As a result, the output of $\mathrm{MRF}$ in a region should be higher on average compared to the output of SRF located in the same region. To test this prediction, I compare firm-region characteristics across firm type by estimating

$$
\ln Z_{f g}=\beta_{s g}+\beta_{m} \mathrm{ID}_{f}^{M R F}+\mu_{f g}
$$

where $g$ indexes region. I consider the same indicators of performance as in Panel A, but define them at the firm-region level (e.g., firm-region output or firm-region productivity). The regressions include a set of region-industry dummy variables such that the point estimates can be interpreted as the average percentage difference between MRF and SRF in the same region-industry. I report OLS regression results in Panel B of Table 3. The results are consistent with the model's predictions. As indicated in the table, MRF are larger and more productive in each region they enter compared to the SRF located in the same region and producing the same good.

Because firm productivity and firm-region demand evolve stochastically over time, the steady state equilibrium of the model features within-firm region switching. To examine the prevalence of firm-level adjustments along the extensive regions margin, I divide firms into 
four exhaustive and mutually exclusive groups. Each category is defined according to the type of changes firms make between Censuses year 2002 and 2007. The four types are: (i) None: the firm has local presence in the same regions in both periods; (ii) Enter only: the firm began producing in one or more additional regions; (iii) Exit only: the firm closed its operations in one or more regions; and (iv) Both enter and exit: the firms began and ceased production in different regions.

Panel A of Table 4 reports the distribution of firms and panel B the distribution of output across the four groups for all firms and for MRF. The empirical results show that only about 4 percent of all firms make adjustments along the extensive margin between 2002 and 2007. However, over the same period of time, more than 70 percent of MRF either entered or exited a region. As reported in the table, firms for which I measure market switching account for more than 75 percent of manufacturing output. These results are consistent with the theoretical model which features steady state market switching by large surviving MRF.

\section{[TABLE 4: HERE]}

In the theoretical model, there is a positive association between firm-level changes in indicators of performance and region switching. While firm-region level demand shocks may generate entry and exit of regions, an increase in firm productivity will, on average, increase the number of regions in which a firm produces output. I evaluate this prediction by regressing $\log$ changes in firm characteristics $\left(\Delta \ln Z_{f}\right)$ on two indicator variables, "NetEnter" which is equal to 1 if the firm produces output in more regions in 2007 than in 2002, and 0 otherwise, and "NetExit" which is equal to 1 if the firm produces in fewer regions in 2007 than in 2002, and 0 otherwise, as well as a set of industry dummy variables $\left(\beta_{s}\right)$

$$
\Delta \ln Z_{f}=\beta_{s}+\beta_{n} N e t \text { Enter }_{f}+\beta_{x} \text { NetExit }_{f}+\mu_{f} .
$$


The omitted category contains firms that operate in the same number of regions in both period. The model predicts that firms receiving good productivity shocks will enter more regions than they exit on average, such that $\beta_{n}>0$ and $\beta_{x}<0$.

I report the results from estimating equation (16) by OLS in Table 5. The sample contains all MRF surviving between 2002 and 2007. As before, the firm characteristics I consider are output, employment, productivity and TFP. As reported in the table, the correlation between region switching and changes in firm-level characteristics are consistent with the predictions of the model. NetEnter is positively associated with changes in firm size and efficiency, whereas the correlation between NetExit and the measures of performance are negative as expected. The point estimates are statistically significant at conventional level except for the impact of NetExit on TFP. I note that region entry and exit is an extensive margin firms use to allocate resource to their best use. As a result, the correlations reported in Table 5 capture both the impact of random shocks and the endogenous entry and interregional sales vs. investment decisions.

\section{[TABLE 5: HERE]}

\subsection{Region entry and exit}

In this section, I study within-firm patterns of region switching to evaluate if they conform to the model's predictions. I begin with region entry. In the model, more productive firms are more likely to enter new regions because of serial correlations in productivity shocks. This implies period $t$ productivity should be positively correlated with entry of regions in subsequent periods $t+k, \forall k \geq 1$. I test this prediction of the model by regressing a firm-level indicator variable, Enter which equals 1 if the firm enters new regions between 2002 and 2007, and 0 otherwise, on initial firm-level measures of productivity and a set of industry dummies $\left(\beta_{s}\right)$

$$
\text { Enter }_{f}=\beta_{s}+\beta_{z} \ln Z_{f}+\mu_{f}
$$


where $Z_{f}$ denotes, in turn, measured firm productivity and TFP in 2002.

I report the results from OLS regressions in Table 6. The results show that region entry decisions are related to initial firm productivity as predicted by the model. As indicated in the table, there is a positive association between (lagged) productivity and the probability of entering new regions. The estimated coefficients on each measure of productivity are statistically significant at the one percent level. Because the regressions include industry dummy variables, the results are not driven by differences in interregional sales and investment costs across industries, or any other industry characteristics.

\section{[TABLE 6: HERE]}

In the theoretical model, there is serial correlation in firm-region level demand shocks. As a result, firms are more likely to cease production in regions where they currently face relatively low demand. Testing this prediction requires information on firm-region demand shocks, which are not directly observed in the data. In the model, dispersion in average output across firms is explained by differences in firm-level productivity and average demand shocks. This implies that within-firm variation in output across regions reflects differences in demand shocks across regions. Following the model, I measure demand shocks using the ratio of firm-region size to firm average size per region (i.e., $\widehat{\lambda}_{f g}=z_{f g} / \bar{z}_{f}$, where $z$ is a measure of size, and $f$ and $g$ denote firm and region indices, respectively).

I explore the correlation between changes in firm-region measures of relative size and firm-region exit patterns by regressing an indicator variable, Exit, which equals 1 if the firm drops a region between 2002 and 2007, and 0 otherwise, on firm-region measures of relative size, as well as industry-region level and firm-level dummy variables ( $\beta_{s g}$ and $\beta_{f}$, respectively)

$$
\operatorname{Exit}_{f g}=\beta_{s g}+\beta_{f}+\beta_{z} \ln Z_{f g}+\mu_{f g}
$$

where $Z_{f g}$ denotes, in turn, measured firm-region revenue and employment in 2002. Because the regressions include region-industry level and firm-level fixed effects, they isolate the 
impact of across-regions variation in size (i.e., the initial demand shocks) on the probability that a firm will exit a region.

I report the results from estimating equation (18) by OLS in Table 7 . The results are consistent with the theoretical model's predictions. As shown in the table, there is a negative association between (relative) firm-region size and the probability of exit. The first column of the table shows firms are more likely to stop producing in regions in which their output is small compared to their output in other regions. The second column of Table 7 shows the result is the same when using employment as a measure of firm-region size. Both point estimates are significant at conventional levels.

\section{[TABLE 7: HERE]}

As reported in Table 2, within-firm adjustments along the regions margin captured in the model are quantitatively important in explaining industry dynamics at the aggregate level. I now explore the importance of this reallocation at the firm-level. To do this, I decompose the total output and employment of surviving multiregional firms in a given Census year according to whether it is related to an incumbent region, a newly added region, or a region that will be dropped. Using the same notation as in section 4.1, the share of total output (or employment) in added and dropped regions can be expressed, respectively, as

$$
\operatorname{Added}_{t+5}=\frac{A_{t+5}^{M R}}{A_{t+5}^{M R}+E_{t+5}^{M R}+C_{t+5}^{M R}}, \quad \text { and } \quad \text { Dropped }_{t}=\frac{T_{t}^{M R}}{E_{t}^{M R}+C_{t}^{M R}+T_{t}^{M R}}
$$

The "Added" variable is backward looking. It presents the share of economic activity in 2007 associated with regions that were added between 2002 and 2007. The "Dropped" variable is forward looking and reports the share of economic activity in 2002 associated with regions that surviving MRF will exit between 2002 and 2007.

I construct the two measures defined in (19) for output and employment. I report the results in Table 8. As shown in the table, regions that were added between 2002 and 2007 account for about 10.4 percent of the firm's output and 8.6 percent of employment on average. 
The relative importance of dropped regions in overall firm's activity is similar, as seen in the last column of the table. At this pace, a firm could completely relocate production in less than 50 years. From Table 1, MRF account for about 66 percent of manufacturing output. Combining this information with the results reported in Table 8 implies that about 6.6 percent of 2007 aggregate manufacturing output was produced by surviving MRF at establishments they did not own in 2002. Again, given the short period of time covered by the sample, this should be viewed as a conservative estimate because new establishments are likely to grow in importance as they age. Nevertheless, the results suggest that within-firm adjustments along the extensive regions margin are not only prevalent but also account for an significant fraction of firm and industry output and employment.

\section{[TABLE 8: HERE]}

\section{$5 \quad$ Robustness and alternate explanations}

For the empirical analysis, I used the EAs as my unit of geography. While these areas are well defined economic markets, it is possible that the definition of a "regional market" varies across industries. In particular, when trade costs are very large it is possible that a firm will open more than one establishment in the same EAs. As a robustness check, I use the number of establishments per firm as an alternative measure of region count. The empirical results of this paper are robust to this change in the definition of regional markets. As expected, the estimated shares of economic activity associated with MRF are larger when using establishment location instead of EAs as the unit of regional market, but these changes are relatively small. This happens because the majority of MRF operate a single establishment in each EAs; the average number of establishments per EAs for MRF is 1.12 in my sample. This finding implies the distance between a firm's establishments is substantial and supports the idea that the decision to open additional establishments is driven by market-seeking consideration and impediments to trade, as emphasized in the theoretical model. 
The theoretical model ignores an important variable that enters the production-location decision of firms: variation in production costs. If production costs are lower in certain regions, firms are more likely to locate production in those regions. In the analysis, I treat the distribution of costs across regions as an industry characteristic that influences the decision of all firms in the industry in the same way. Because my estimating equations control for industry-level effects (or industry-region level effects when appropriate), they provide information on across-firms and within-firm changes in the geographic distribution of production conditional on industry (or industry-region) characteristics. More importantly, I note that differences in costs across regions may provide a natural explanation for the concentration of industry production in a few regions (e.g., Gervais and Jensen (2013)), but it does not help explain differences in the geographic dispersion of output for firms in the same industry.

The model emphasizes the market-seeking motive for opening additional establishments such that there is no differentiation in products across establishments within the firm. Accordingly, I define industries at the six-digit NAICS level, the most disaggregate classification available. Nevertheless, there may be within-firm variation across regions at the (undefined) seven-digits NAICS level. The empirical results of this paper are unlikely to be driven by unobserved product-level variation. First, as shown in Bernard et al. (2010), roughly 85 percent of added and dropped products are, respectively, added and dropped at surviving establishments. This implies that the probability that regions switching is driven by an expansion or contraction of the product line is small. Second, the main results hold in a restricted sample that includes only homogenous industries, as defined in Rauch (1999).

\section{Conclusion}

A robust finding of the literature on industry dynamics is that reallocation of resources toward more efficient producers is an important source of aggregate productivity growth 
and within-industry employment churning. So far, empirical studies have focused on the impact of reallocation across-producers within the same industry. In this paper, I explore the contribution of an adjustment margin within the firm that has been so far ignored: "market switching."

To guide the empirical analysis, I develop a natural extension of existing models of industry dynamics that introduces endogenous production-location decisions within firms. In the model, firms respond to productivity and demand shocks by adjusting the price they charge in each region, the number of regions they serve, and the distribution of production across these regions. The model is a generalization of current models of production-location decision that allows for time series variation in firm productivity and firm-region demand shocks.

I test the model's predictions using a new dataset on manufacturing firms derived from the US Census of manufactures. The data provides information on the spatial distribution of firms production and tracks changes in that distribution over time. I find that market switching is common among large US manufacturing firms and is correlated with changes in firm characteristics in ways predicted by the theoretical model. In the data, an increase in firm productivity (both within- and across-firms) is associated with an increase in the geographic dispersion of production. 


\section{References}

Allouch, C., P. Sablonnière, and D. Sbibih (2012). Collocation methods for solving multivariable integral equations of the second kind. Journal of Computational and Applied Mathematics 236(17), 4494-4512.

Baily, M. N., C. Hulten, D. Campbell, T. Bresnahan, and R. E. Caves (1992). Productivity dynamics in manufacturing plants. Brookings papers on economic activity. Microeconomics, $187-267$.

Bartelsman, E. J. and M. Doms (2000). Understanding productivity: Lessons from longitudinal microdata. Journal of Economic literature 38(3), 569-594.

Bernard, A. B., J. B. Jensen, and P. K. Schott (2009). Importers, exporters and multinationals: a portrait of firms in the US that trade goods. In Producer dynamics: New evidence from micro data, pp. 513-552. University of Chicago Press, Chicago, IL.

Bernard, A. B., S. Redding, and P. K. Schott (2010). Multiple-product firms and product switching. American Economic Review 100(1), 70-97.

Bernard, A. B., S. J. Redding, and P. K. Schott (2011). Multiproduct firms and trade liberalization. Quarterly Journal of Economics 126(3), 1271-1318.

Brainard, S. L. (1997). An empirical assessment of the proximity-concentration trade-off between multinational sales and trade. American Economic Review 87(4), 520-44.

Davis, S. J. and J. Haltiwanger (1992). Gross job creation, gross job destruction, and employment reallocation. The Quarterly Journal of Economics 107(3), 819-863.

Dunne, T., M. J. Roberts, and L. Samuelson (1989). The growth and failure of us manufacturing plants. Quarterly Journal of Economics 104(4), 671-698. 
Ericson, R. and A. Pakes (1995). Markov-perfect industry dynamics: A framework for empirical work. Review of Economic Studies 62(1), 53-82.

Foster, L., J. Haltiwanger, and C. Syverson (2008). Reallocation, firm turnover, and efficiency: Selection on productivity or profitability? American Economic Review 98(1), 394-425.

Foster, L., J. C. Haltiwanger, and C. J. Krizan (2001). Aggregate productivity growth: Lessons from microeconomic evidence. In E. R. D. Charles R. Hulten and M. J. Harper (Eds.), New developments in productivity analysis, pp. 303-372. University of Chicago Press, Chicago, IL.

Gervais, A. (2013). Product quality and firm heterogeneity in international trade. Center for Economic Studies Paper No. CES-WP-13-08.

Gervais, A. and J. B. Jensen (2013). The tradability of services: Geographic concentration and trade costs. National Bureau of Economic Research.

Goldberg, P. K., A. K. Khandelwal, N. Pavcnik, and P. Topalova (2010). Multiproduct firms and product turnover in the developing world: Evidence from india. Review of Economics and Statistics 92(4), 1042-1049.

Hallak, J. C. and J. Sivadasan (2013). Product and process productivity: Implications for quality choice and conditional exporter premia. Journal of International Economics $91(1)$, 53-67.

Helpman, E., M. J. Melitz, and S. R. Yeaple (2004). Export versus fdi with heterogeneous firms. American economic review 94(1), 300-316.

Hopenhayn, H. A. (1992). Entry, exit, and firm dynamics in long run equilibrium. Econometrica $60(5), 1127-1150$.

Iacovone, L. and B. S. Javorcik (2010). Multi-product exporters: Product churning, uncertainty and export discoveries. Economic Journal 120(544), 481-499. 
Internal Revenue Service (2014). Employer identification number: Understanding your EIN. Department of the Treasury, Publication 1635.

Jarmin, R. S. and J. Miranda (2002). The longitudinal business database. Center for Economic Studies Discussion Paper CES-WP-02-17.

Johnson, K. P. and J. R. Kort (2004). 2004 redefinition of the bea economic areas. Survey of Current Business 84(11), 68-75.

Johnson, R. C. (2012). Trade and prices with heterogeneous firms. Journal of International Economics 86(1), 43-56.

Jovanovic, B. (1982). Selection and the evolution of industry. Econometrica 50(3), 649-670.

Kolmogorov, A. N. and S. V. Fomin (1970). Introductory real analysis. Prentice-Hall Inc., Englewood Cliffs, NJ.

Kugler, M. and E. Verhoogen (2012). Prices, plant size, and product quality. Review of Economic Studies $79(1), 307-339$.

Mayer, T., M. J. Melitz, and G. I. Ottaviano (2014). Market size, competition, and the product mix of exporters. American Economic Review 104(2), 495-536.

Melitz, M. (2003). The impact of trade on intra-industry reallocations and aggregate industry productivity. Econometrica $71(6), 1695-1725$.

Qiu, L. D. and W. Zhou (2013). Multiproduct firms and scope adjustment in globalization. Journal of International Economics 91(1), 142-153.

Ramondo, N. and A. Rodríguez-Clare (2013). Trade, multinational production, and the gains from openness. Journal of Political Economy 121(2), 273-322.

Rossi-Hansberg, E. and M. L. Wright (2007). Establishment size dynamics in the aggregate economy. American Economic Review 97(5), 1639-1666. 
Schumpeter, J. (1942). Capitalism, socialism and democracy. Harper and Row, New York, $N Y$.

Timoshenko, O. A. (2014). Product switching in a model of learning. Journal of International Economics 95(2), 233-249.

United States Census Bureau (2007). History of the 2007 economic census. United States Department of Commerce. 
TABLE 1

Prevalence of multiregional manufacturing firms, 2007

\begin{tabular}{lc}
\hline \hline & Multiregional Firms \\
\hline Percent of firms & 3 \\
Percent of output & 66 \\
Percent of employment & 46 \\
Mean number of regions & 3.64 \\
\hline
\end{tabular}

Notes: This table presents the share of US manufacturing firms that operate in multiple regions, as well as the share of output and employment these firms account for. The table also presents the mean number of regions across multiregional firms. A firm is defined as a set of establishments that produce output classified in the same six-digit NAICS category and are own by the same company. The statistics are computed from a sample of more than 294,000 establishments. 
TABLE 2

Decomposition of Net CHANGEs, 2002 to 2007

\begin{tabular}{lcc}
\hline \hline & Output & Employment \\
\hline Net percentage change & 6.12 & -1.92 \\
Firm birth, $B$ & 4.44 & 5.16 \\
Multiregional firms & & \\
$\quad$ Entry, $A^{M R F}$ & 3.15 & 1.86 \\
$\quad$ Expansion, $E^{M R F}$ & 4.36 & 0.88 \\
$\quad$ Contraction, $C^{M R F}$ & -0.78 & -1.33 \\
$\quad$ Exit, $T^{M R F}$ & -2.23 & -2.17 \\
Single-region firms & & \\
$\quad$ Expansion, $E^{S R F}$ & 1.68 & 1.31 \\
$\quad$ Contraction, $C^{S R F}$ & -0.38 & -1.08 \\
Firm death, $D$ & -4.11 & -6.55 \\
\hline
\end{tabular}

Notes: This table decomposes the net percentage change per year in manufacturing output and employment into eight mutually exclusive and exhaustive types of region-level adjustments. Growth rates are defined as changes between years divided by the average of base and end-year variables. A firm is defined as a set of establishments that produce output classified in the same six-digit NAICS category and are own by the same company. The statistics are computed from a sample of more than 294,000 manufacturing establishments. 
TABLE 3

Single- VS. MULTI-REgION FIRMS CHARACTERISTICS, 2007

\begin{tabular}{lc}
\hline \hline \multicolumn{1}{c}{ Multiregional firm indicator } \\
\hline Panel A: Differences between firms \\
Output & $2.60(0.05)[0.43]$ \\
Employment & $2.23(0.04)[0.34]$ \\
Productivity & $0.43(0.02)[0.18]$ \\
TFP & $0.07(0.01)[0.48]$ \\
\hline Panel B: Differences between firm-regions \\
Output & $1.43(0.02)[0.59]$ \\
Employment & $1.04(0.01)[0.49]$ \\
Productivity & $0.32(0.01)[0.42]$ \\
TFP & $0.04(0.00)[0.60]$ \\
\hline
\end{tabular}

Notes: Panel A presents the results from 4 separate OLS regressions of log firm characteristics on a dummy variable equal to one if the firm operates in multiple regions and industry fixed effects. Panel B presents the results from OLS regressions of log firm-region characteristics on the same dummy variable and region-industry fixed effects. Standard errors clustered by industry in panel A and industry-region in panel B are in parenthesis. The $R^{2}$ is in square brackets for each regression. All differences are statistically significant at the one percent level. A firm is defined as a set of establishments that produce output classified in the same six-digit NAICS category and are own by the same company. The statistics for panels A and $\mathrm{B}$ are computed from a sample of more than 69,000 manufacturing firms and more than 102,000 firm-region observations, respectively. 
TABLE 4

REGION SWITCHING BY MANUFACTURING FIRMS, 2002 TO 2007

\begin{tabular}{lcc}
\hline \hline Firm activity & All firms & Multiregional firms \\
\hline Panel A. Share of firms & & \\
None & 96 & 29 \\
Enter only & 1 & 20 \\
Exit only & 1 & 23 \\
Both enter and exit & 2 & 28 \\
\hline Panel B. Share of output & & \\
None & 42 & 24 \\
Enter only & 15 & 20 \\
Exit only & 20 & 26 \\
Both enter and exit & 23 & 30 \\
\hline
\end{tabular}

Notes: This table presents the distribution of surviving firms across four exhaustive and mutually exclusive categories of region switching activity. A firm is defined as a set of establishments that produce output classified in the same six-digit NAICS category and are own by the same company. The statistics are computed from a sample of more than 294,000 manufacturing establishments. 
TABLE 5

REGION SWITCHING AND CHANGES IN FIRMS CHARACTERISTICS, 2002 TO 2007

\begin{tabular}{lccc}
\hline \hline Log change & Net enter & Net exit & $R^{2}$ \\
\hline Output & $0.191^{* *}$ & $-0.316^{* *}$ & 0.076 \\
Employment & $(0.007)$ & $(0.015)$ & \\
& $0.189^{* *}$ & $-0.381^{* *}$ & 0.068 \\
Productivity & $(0.010)$ & $(0.016)$ & \\
& $0.044^{* *}$ & $-0.019^{*}$ & 0.020 \\
TFP & $(0.009)$ & $(0.009)$ & \\
& $0.018^{* *}$ & -0.003 & 0.060 \\
\hline
\end{tabular}

Notes: This table presents the results of OLS regressions of log change in firm characteristics on two indicator variables: "Net enter" which is equal to 1 if the firm adds more regions than it drops between 2002 and 2007, and 0 otherwise, and "Net exit" which is equal to 1 if the firm drops more regions than it adds over the same period, and 0 otherwise. The omitted category comprises firms for which the number of regions is the same in both periods. The dependent variables are defined as the log of changes between years divided by the average of base and end-year variables. The regressions include six-digit NAICS industry dummies. Each line presents the results of four separate regressions, one for each of the noted dependent variables. Robust standard errors in parentheses are adjusted for clustering by industry. A $*$ and a $* *$ indicate significance at the 5 and 1 percent level, respectively. The statistics are computed from a sample of more than 69,000 firms. 
TABLE 6

REGION ADDING AND FIRM CHARACTERISTICS, 2002 TO 2007

\begin{tabular}{lcc}
\hline \hline Variable & Add & Add \\
\hline Log productivity $t$ & $0.018^{* *}$ & \\
Log TFP $_{t}$ & $(0.001)$ & $0.009^{* *}$ \\
& & $(0.001)$ \\
$R^{2}$ & 0.074 & 0.067 \\
\hline
\end{tabular}

Notes: The table reports the results of OLS regressions of a dummy variable equal to 1 if the firm adds one or more regions between census years 2002 and 2007, on 2002 firm attributes and industry fixed effects. Robust standard errors in parentheses are adjusted for clustering by industry. $\mathrm{A} *$ and a $* *$ indicate significance at the 5 and 1 percent level, respectively. The statistics are computed from a sample of more than 69,000 firms. 
TABLE 7

REGION EXIT AND FIRM-REGION CHARACTERISTICS, 2002 TO 2007

\begin{tabular}{lcc}
\hline \hline Variable & Exit & Exit \\
\hline Log (relative) revenue $t$ & $-0.136^{* *}$ & \\
Log (relative) employment & $(0.005)$ & $-0.068^{* *}$ \\
$R^{2}$ & & $(0.002)$ \\
\hline
\end{tabular}

Notes: The table reports the results of OLS regressions of an indicator variable equal to 1 if a firm exits a region between 2002 and 2007, and 0 otherwise, on measures of firm-region size. Regressions include industry-region fixed effects. Robust standard errors in parentheses are adjusted for clustering by region-industry. $\mathrm{A} *$ and a $* *$ indicate significance at the 5 and 1 percent level, respectively. The statistics are computed from a sample of more than 102,000 firm-region observations. 
TABLE 8

DISTRIBUTION OF ECONOMIC ACTIVITY ACROSS REGION TYPE

\begin{tabular}{lcc}
\hline \hline & Added & Dropped \\
\hline Share of Sales & 10.4 & 10.2 \\
Share of Employment & 8.6 & 9.5 \\
\hline
\end{tabular}

Notes: This table presents the distribution of firm-regions, sales and employment across region type. The "Added" column reports 2007 number of regions, sales and employment as a proportion of corresponding 2007 total values. The "Dropped" column reports 2002 number of regions, sales and employment as a proportion of corresponding 2002 total values. The 2002 and 2007 samples include all manufacturing establishments active in each of the Censuses year. 


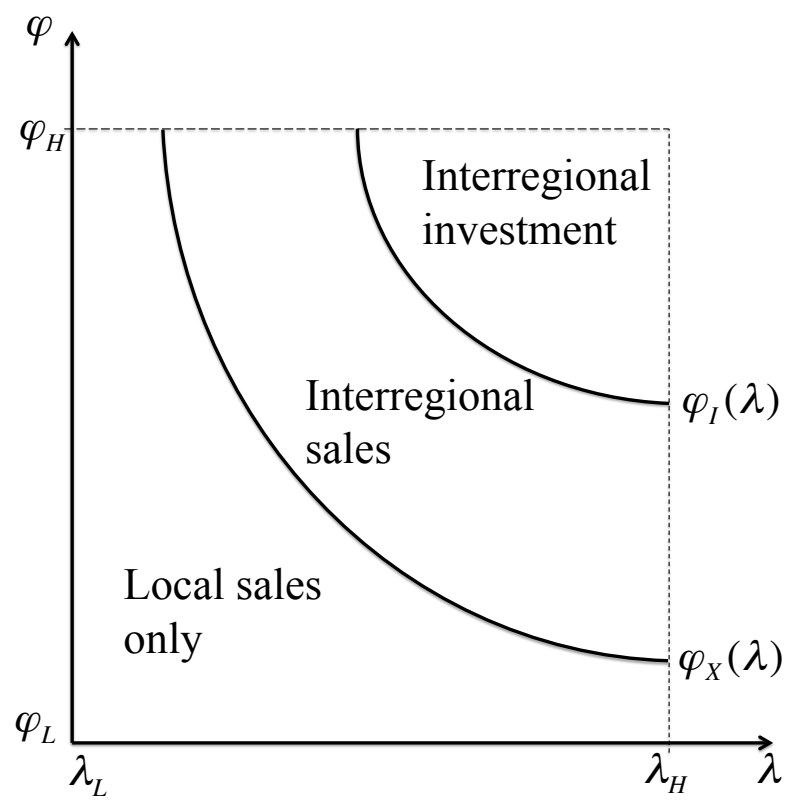

Figure 1: FIRM SORTING ACROSS PRODUCTIVITY AND DEMAND SHOCKS 


\section{Appendix}

This Appendix has two main sections. In the first section, I describe the general equilibrium of the model. In the second section, I analyze the implications of the model for market switching.

\section{A Equilibrium}

The main text discusses only firm-level decisions. In this section, I complete the characterization of the equilibrium by solving for the aggregate variables.

\section{A.1 Labor market clearing}

The labor market clearing condition requires that the demand for labor be equal to the supply of labor. Because labor does not enter the utility function, consumers always provide their unit of labor to the market. This implies that the supply of labor is always equal to the mass of consumers, $L$. There are two sources of demand for labor. Incumbent firms demand $L_{P}$ units of labor for production, and entrants demand $L_{E}$ units of labor to pay the entry costs. Therefore, the labor market clearing condition implies that $L=L_{P}+L_{E}=L_{P}+M_{E} f_{E}$, where $M_{E}$ denotes the mass of potential entrants. From the free entry condition, it must be the case that the expected value of entry equals fixed entry costs, $\bar{v}=f_{E}$. At the same time, stationarity requires that the mass of entrant equals the mass of firms forced to exit, $M_{E}=\delta M$. Together, these results imply that

$$
L_{E}=M_{E} f_{E}=\delta M \bar{v}
$$

Firms are assumed to finance the entry cost by issuing equity. Since there is a continuum of firms, and the productivity and consumer tastes distributions are independent across firms, consumers can diversify away the idiosyncratic risk of stochastic shocks to firm's productivity and demand. Equation (20) implies that payments to labor used in entry equal the rate of 
return received on the average value of the firm, which implies consumers break even on their equity holdings.

Aggregate revenue are divided into payroll to production workers and return on equity to shareholders as follows: $R=L_{P}+\delta M \bar{v}$. This implies that payroll is given by $L_{P}=R-\delta M \bar{v}$ (recall that, without loss of generality, the wage rate is normalized to 1). Using this result along with (20) in the labor market clearing condition imply that $L=R-\delta M \bar{v}+\delta M \bar{v}=R$. Therefore, equilibrium expenditure is equal to the size of the labor force.

\section{A.2 Stationary distributions}

In a stationary equilibrium, the flows in and out of each value of productivity and demand parameter must be equal. These flows depend on the distributions from which these variables are drawn upon entry and the conditional distributions from which they are drawn following a stochastic shock. Productivity stationarity requires that, for each level of productivity

$$
\delta M \bar{g}(\varphi)=M_{E} g_{E}(\varphi)+M \int_{\varphi_{L}}^{\varphi_{H}} g_{C}(\varphi \mid \psi) \bar{g}(\psi) d \psi
$$

where $\bar{g}(\varphi)$ denotes the stationary probability density function (pdf) of productivity with

cumulative distribution $\bar{G}(\varphi), g_{E}(\varphi)$ is the pdf of the entry distribution of productivity $G_{E}(\varphi)$, and $\delta, M_{E}$, and $M$ are constants. The left hand side of the equation represents the outflow of firms hit by the bad shock and forced to exit. The first term on the right-hand side denotes the inflow of new entrants in the industry and the second term is the inflow of firms due to productivity shocks.

Recall that stationarity requires $M_{E}=\delta M$. Therefore, dividing both sides of equation (21) by $\delta M$ yields

$$
\bar{g}(\varphi)=g_{E}(\varphi)+\frac{1}{\delta} \int_{\varphi_{L}}^{\varphi_{H}} g_{C}(\varphi \mid \psi) \bar{g}(\psi) d \psi
$$


Equation (22) is a non-homogeneous Fredholm equation (a.k.a. Fredholm equation of the second kind). Under the maintained assumptions, the two (known) functions $g_{E}(\varphi)$ and $g_{C}(\varphi \mid \psi)$ are continuous on bounded sets. If there is a constant $Z$ such that $g_{C}(\varphi \mid \psi) \leq Z<\delta$, there exists a unique solution to the integral (Kolmogorov and Fomin (1970)). As a result, there exists a unique stationary distribution of firm productivity. Note that the equilibrium distribution does not depend on the size of the economy ( $L$ or $M$ ).

Similarly, the stationary distribution of demand across varieties must satisfy

$$
\delta M \bar{h}(\lambda)=M_{E} h_{E}(\lambda)+M \int_{\lambda_{L}}^{\lambda_{H}} h_{C}(\lambda \mid \psi) \bar{h}(\psi) d \psi
$$

where $\bar{h}(\lambda)$ denotes the stationary probability density function (pdf) of demand with cumulative distribution $\bar{H}(\lambda), h_{E}(\lambda)$ is the pdf of the entry distribution of productivity $H_{E}(\lambda)$, and $\delta, M_{E}$, and $M$ are constants. The left-hand side of the equation represents the outflow of firms hit by the bad shock and forced to exit. The first term and second term on the right-hand side denote the inflow due to new entrants and demand shocks. Equation (23) can also be written in the form of a Fredhom integral and the conditions for existence and uniqueness are similar as those discussed for equation (22).

\section{A.3 Bellman equation}

I now discuss the solution to the Bellman equation (9) which defines the value of the firm and the equilibrium mass of firms. Consider the following trial solution

$$
v\left(\varphi^{\prime}, \boldsymbol{\Lambda}^{\prime}\right)=a \pi\left(\varphi^{\prime}, \boldsymbol{\Lambda}^{\prime}\right)+b \int_{\varphi} \int_{\boldsymbol{\Lambda}} \eta\left(\varphi^{\prime \prime}, \boldsymbol{\Lambda}^{\prime \prime}\right) \pi\left(\varphi^{\prime \prime}, \boldsymbol{\Lambda}^{\prime \prime}\right) d H_{C}\left(\boldsymbol{\Lambda}^{\prime \prime} \mid \boldsymbol{\Lambda}^{\prime}\right) d G_{C}\left(\varphi^{\prime \prime}, \varphi^{\prime}\right),
$$


where $a$ and $b$ are parameters and $\eta(\varphi, \boldsymbol{\Lambda})$ is a function to be determined. Replacing with the trial solution (24) in the Bellman equation (9) yields

$$
\begin{aligned}
v(\varphi, \boldsymbol{\Lambda})= & \pi(\varphi, \boldsymbol{\Lambda}) \\
& +(1-\delta) \int_{\varphi} \int_{\boldsymbol{\Lambda}}\left[\frac{a \pi\left(\varphi^{\prime}, \boldsymbol{\Lambda}^{\prime}\right)+b \iint \eta\left(\varphi^{\prime \prime}, \boldsymbol{\Lambda}^{\prime \prime}\right) \pi\left(\varphi^{\prime \prime}, \boldsymbol{\Lambda}^{\prime \prime}\right) d \mathscr{H}_{C}\left(\boldsymbol{\Lambda}^{\prime \prime} \mid \boldsymbol{\Lambda}^{\prime}\right) d G_{C}\left(\varphi^{\prime \prime}, \varphi^{\prime}\right)}{\pi\left(\varphi^{\prime}, \boldsymbol{\Lambda}^{\prime}\right)}\right] d \mathscr{H}_{C}\left(\boldsymbol{\Lambda}^{\prime} \mid \boldsymbol{\Lambda}\right) d G_{C}\left(\varphi^{\prime}, \varphi\right),
\end{aligned}
$$

where $\mathscr{H}_{C}(\boldsymbol{\Lambda}) \equiv \prod_{N} H_{C}(\lambda)$. This implies that $a=1$ and $b=1-\delta$ and

$$
\eta(\varphi, \boldsymbol{\Lambda})=1+(1-\delta) \int_{\varphi} \int_{\boldsymbol{\Lambda}} K\left(\varphi, \boldsymbol{\Lambda}, \varphi^{\prime}, \boldsymbol{\Lambda}^{\prime}\right) \eta\left(\varphi^{\prime}, \boldsymbol{\Lambda}^{\prime}\right) d H_{C}\left(\boldsymbol{\Lambda}^{\prime} \mid \boldsymbol{\Lambda}\right) d G_{C}\left(\varphi^{\prime}, \varphi\right)
$$

where $K\left(\varphi, \boldsymbol{\Lambda}, \varphi^{\prime}, \boldsymbol{\Lambda}^{\prime}\right)=\pi\left(\varphi^{\prime}, \boldsymbol{\Lambda}^{\prime}\right) / \pi(\varphi, \boldsymbol{\Lambda})$ is a know continuous function defined over bounded sets. The solution for $\eta(\varphi, \boldsymbol{\Lambda})$ is a non-homogeneous multivariate Fredholm integral. Conditions for existence and uniqueness are discussed in Allouch et al. (2012).

\section{A.4 Export productivity threshold}

Using the structure of the model, it is possible to express firm conditional profits as a function

of the productivity threshold for interregional sales and demand shocks only. ${ }^{18}$ From the definition of $\varphi_{x}, \pi\left(\varphi_{x}, \lambda_{H}\right)=0$ such that $r_{X}\left(\varphi_{x}, \lambda_{H}\right)=\varepsilon f_{X}$. It follows that

$$
\begin{aligned}
& r_{D}(\varphi, \lambda)=\left(\frac{\tau \varphi \lambda}{\varphi_{X} \lambda_{H}}\right)^{\varepsilon-1} f_{X}, \quad \pi_{D}(\varphi, \lambda)=\left(\frac{\tau \varphi \lambda}{\varphi_{X} \lambda_{H}}\right)^{\varepsilon-1} f_{X} \\
& r_{X}(\varphi, \lambda)=\left(\frac{\varphi \lambda}{\varphi_{X} \lambda_{H}}\right)^{\varepsilon-1} f_{X}, \quad \pi_{X}(\varphi, \lambda)=\left[\left(\frac{\varphi \lambda}{\varphi_{X} \lambda_{H}}\right)^{\varepsilon-1}-1\right] f_{X} \\
& r_{I}(\varphi, \lambda)=\left(\frac{\tau \varphi \lambda}{\varphi_{X} \lambda_{H}}\right)^{\varepsilon-1} f_{X}, \quad \text { and } \pi_{X}(\varphi, \lambda)=\left[\left(\frac{\tau \varphi \lambda}{\varphi_{X} \lambda_{H}}\right)^{\varepsilon-1}-1\right] f_{X} .
\end{aligned}
$$

Further, using the definition for the productivity thresholds in (6) and making use of the fact that $\varphi_{x} \lambda_{H}=\left(\varepsilon f_{X} / R\right)^{1 /(\varepsilon-1)} \tau / P \rho$, it follows that $I_{X}(\varphi, \lambda)=1$ if and only if $\lambda>\lambda_{H} \varphi_{X} / \varphi$ and $\varphi>\varphi_{X}$, and 0 otherwise. Similarly, $I_{I}(\varphi, \lambda)=1$ if and only if $\lambda>\lambda_{H} \varphi_{X} / \tau \varphi$ and

\footnotetext{
${ }^{18}$ Melitz (2003) solves for the profitability threshold for survival in the industry. In the current model, this is always the lower bound productivity $\varphi_{L}$. This happens because there is no domestic production costs. Instead, I solve for the productivity threshold above which firms engage in interregional sales.
} 
$\varphi^{\varepsilon-1}>\left(f_{I}-f_{X}\right) \varphi_{X} / f_{X}\left(\tau^{\varepsilon-1}-1\right)$, and 0 otherwise. Using these results into the definition of profit (8) shows that firm conditional profits depends only on the export profitability threshold $\varphi_{X}$. The results also make clear that firm profits are monotonically decreasing in the export profitability threshold, $\partial \pi(\varphi, \lambda) / \partial \varphi_{x}<0$.

Using the solution for the firm value function, given in equation (26), into the free entry condition (10) and differentiating with respect to the export threshold, $\varphi_{x}$, yields

$$
\begin{aligned}
\frac{\partial \bar{v}}{\partial \varphi_{X}}=\int_{\varphi} \int_{\boldsymbol{\Lambda}}[ & \frac{\partial \pi(\varphi, \boldsymbol{\Lambda})}{\partial \varphi_{X}}+(1-\delta) \int_{\varphi} \int_{\boldsymbol{\Lambda}} \frac{\partial \eta\left(\varphi^{\prime}, \boldsymbol{\Lambda}^{\prime}\right)}{\partial \varphi_{X}} \pi\left(\varphi^{\prime}, \boldsymbol{\Lambda}^{\prime}\right) d \mathscr{H}_{C}\left(\boldsymbol{\Lambda}^{\prime} \mid \boldsymbol{\Lambda}\right) d G_{C}\left(\varphi^{\prime} \mid \varphi\right) \\
& \left.+(1-\delta) \int_{\varphi} \int_{\boldsymbol{\Lambda}} \eta\left(\varphi^{\prime}, \boldsymbol{\Lambda}^{\prime}\right) \frac{\partial \pi\left(\varphi^{\prime}, \boldsymbol{\Lambda}^{\prime}\right)}{\partial \varphi_{X}} d \mathscr{H}_{C}\left(\boldsymbol{\Lambda}^{\prime} \mid \boldsymbol{\Lambda}\right) d G_{C}\left(\varphi^{\prime} \mid \varphi\right)\right] d \mathscr{H}(\boldsymbol{\Lambda}) d G(\varphi) .
\end{aligned}
$$

The first and last term in the square bracket are negative because an increase in export threshold reduces profits for all firms (i.e., $\partial \pi / \partial \varphi_{X}<0$ ). By definition, as $\delta \rightarrow 1, \eta(\varphi, \boldsymbol{\Lambda}) \rightarrow 1$, and $\partial \eta / \partial \varphi_{X}=0$, such that the second term in the square bracket goes to zero. Also, as in Bernard et al. (2010), when the probability of receiving shock becomes small (i.e., $G_{C}(\varphi \mid \varphi) \rightarrow 1$ and $\left.H_{C}(\lambda \mid \lambda) \rightarrow 1\right), \eta(\varphi, \boldsymbol{\Lambda}) \rightarrow 1 / \delta$ and $\partial \eta / \partial \varphi_{X}=0$, and the second term in the square bracket goes to zero. Therefore, for large enough values of exit shock $\delta$ or small enough probability of productivity and demand shocks, $\bar{v}$ is monotonically decreasing in $\varphi_{X}$. As shown in the free entry condition (10), firms will continue to enter the industry until the expected value of entry is equal to the entry costs such that there exists a unique equilibrium value of $\varphi_{X}^{*}$ for each value of the fixed entry costs $f_{E}$.

\section{A.5 Equilibrium mass of firms}

The equilibrium mass of producing firms can be determined by dividing aggregate revenue, $R$, by the average revenue of a firm conditional on production, $\bar{r}$

$$
M=\frac{R}{\bar{r}}, \quad \text { with } \quad \bar{r}=\int_{\varphi} \int_{\boldsymbol{\Lambda}} r(\varphi, \boldsymbol{\Lambda}) d \mathscr{H}(\boldsymbol{\Lambda}) d G(\varphi)
$$


where revenue across all markets for a firm with productivity $\varphi$ and demand shocks $\boldsymbol{\Lambda}$, $r(\varphi, \boldsymbol{\Lambda})$, can be constructed from equation (27) and depends only on the export productivity threshold $\varphi_{x}^{*}$ and the stationary distribution of productivity and tastes.

\section{A.6 Price index}

The price index is a function of the mass of firms in each market and the distribution of firms in productivity-demand space. It is defined as

$$
\begin{aligned}
P^{\varepsilon-1}=\int_{x} p(x)^{1-\varepsilon} d x=M \rho^{\varepsilon-1}[ & \int_{\varphi_{L}}^{\varphi_{H}} \varphi^{\varepsilon-1} d \bar{G}(\varphi) \\
& +(N-1) \tau^{1-\varepsilon} \int_{\varphi_{X}^{*}}^{\varphi_{I}^{*}}\left[\bar{H}\left(\lambda_{I}(\varphi)\right)-\bar{H}\left(\lambda_{X}(\varphi)\right)\right] \varphi^{\varepsilon-1} d \bar{G}(\varphi) \\
& \left.+(N-1) \int_{\varphi_{I}^{*}}^{\varphi_{H}}\left[1-\bar{H}\left(\lambda_{I}(\varphi)\right)\right] \varphi^{\varepsilon-1} d \bar{G}(\varphi)\right],
\end{aligned}
$$

where $\bar{G}(\varphi)$ and $\bar{H}(\lambda)$ represent the stationary distribution of productivity and demand defined from equations (21) and (23), and $N$ denotes the number of regions. The first term in square bracket is the contribution of domestic firms to the price index, while the second and third terms capture the effects of interregional sales and investment firms, respectively. Given a mass of firms, stationary distribution for productivity and tastes shocks, and the export productivity threshold, it is possible to compute the equilibrium price index. This completes the characterization of the unique equilibrium of the model.

\section{B Analysis}

In this section, I show how the features of market switching that motivate the empirical analysis can be derived from the theoretical model. 


\section{B.1 Multiregional vs. single-region firms}

The revenue of region- $i$ firm depends on productivity and demand shocks as follows

$$
r_{i}(\varphi, \boldsymbol{\Lambda})=\left[1+\tau^{1-\varepsilon} \sum_{j \neq i} I_{X}^{j}(\varphi, \boldsymbol{\Lambda}) \lambda_{j}+\sum_{j \neq i} I_{I}^{j}(\varphi, \boldsymbol{\Lambda}) \lambda_{j}\right] A \varphi^{\varepsilon-1} .
$$

This equation shows that revenue is increasing in firm productivity because revenue per market is greater and the probability of serving multiple markets is higher

$$
\frac{\partial r_{i}(\varphi, \boldsymbol{\Lambda})}{\partial \varphi}=(\varepsilon-1) \frac{r_{i}}{\varphi}+\left[\tau^{1-\varepsilon} \sum_{j \neq i} \lambda_{j} \frac{\partial I_{X}^{j}(\varphi, \boldsymbol{\Lambda})}{\partial \varphi}+\sum_{j \neq i} \lambda_{j} \frac{\partial I_{I}^{j}(\varphi, \boldsymbol{\Lambda})}{\partial \varphi}\right] A \varphi^{\varepsilon-1}>0 .
$$

The inequality follows because the probability of interregional sales or investment is increasing in firm productivity

$$
\frac{\partial I_{k}^{j}(\varphi, \boldsymbol{\Lambda})}{\partial \varphi}=-\frac{\partial \bar{H}\left[\lambda_{k}(\varphi)\right]}{\partial \lambda} \cdot \frac{\partial \lambda_{k}(\varphi)}{\partial \varphi}=\frac{\bar{h}\left[\lambda_{k}(\varphi)\right] \cdot \lambda_{k}(\varphi)}{\varphi}>0, \text { for } k \in X, I
$$

and revenue from local subsidiary sales are higher then revenue from interregional sales (i.e., $\tau^{1-\varepsilon}<1$ ). From that result, it is clear that the average revenue across demand shocks (i.e., $\left.\bar{r}_{i}(\varphi)=\int_{\boldsymbol{\Lambda}} r_{i}(\varphi, \boldsymbol{\Lambda}) d \boldsymbol{\Lambda}\right)$ will be increasing in firm productivity. The probability that a firm is a MRF is given by $P\left(I_{I}=1 \mid \varphi\right)=\bar{H}\left[\lambda_{I}(\varphi)\right]$. As shown in equation (33), this probability is increasing in firm productivity. It follows that more productive firms are larger on average and more likely to be MRF.

\section{B.2 Empirical patterns of region switching}

The model features steady-state region entry and exit within firms as a result of idiosyncratic firm productivity shocks and firm-region demand shocks. The extent of steady-state region switching depends on the number of regions that are not currently served through local 
subsidiary by a firm with productivity $\varphi$, which depends on the stationary distribution of demand shocks $\bar{H}(\lambda)$.

The probability that a firm will open a new subsidiary equals to the probability of drawing a productivity and demand shocks pair such that the firms interregional investment provides the highest (non-negative) profits in that region, i.e., $P\left(I_{I}^{j}\left(\varphi_{t+1}, \boldsymbol{\Lambda}_{t+1}\right)=1 \mid I_{I}^{j}\left(\varphi_{t}, \boldsymbol{\Lambda}_{t}\right)=0\right)$. This probability is increasing in firm productivity for two reasons. First, the probability of drawing a high productivity shock is increasing in current productivity. Second, the range of demand shocks for which the firm finds interregional investment optimal is increasing in productivity.

The probability that a firm will stop production in a region is given by $P\left(I_{I}^{j}\left(\varphi_{t+1}, \boldsymbol{\Lambda}_{t+1}\right)=\right.$ $\left.0 \mid I_{I}^{j}\left(\varphi_{t}, \boldsymbol{\Lambda}_{t}\right)=1\right)$. This probability is decreasing in firm productivity because the probability of drawing a new productivity lower than the current productivity is decreasing in productivity, and the range of demand shocks for which the firm finds interregional investment optimal is increasing in productivity. To exit a region and survive, the firms need to have an establishment in at least two regions. This implies that region switching will be concentrated amongst the most productive firms in the industry.

The expected net change in the number of establishments owned by a firm (i.e., the number of regions with local presence) is given by the sum across regions over the probabilities of entering a region and exiting a region

$$
\sum_{j} P\left(I_{I}^{j}\left(\varphi_{t+1}, \boldsymbol{\Lambda}_{t+1}\right)=0 \mid I_{I}^{j}\left(\varphi_{t}, \boldsymbol{\Lambda}_{t}\right)=1\right)+P\left(I_{I}^{j}\left(\varphi_{t+1}, \boldsymbol{\Lambda}_{t+1}\right)=0 \mid I_{I}^{j}\left(\varphi_{t}, \boldsymbol{\Lambda}_{t}\right)=1\right) .
$$

Because the probability of entry is increasing in productivity and the probability of exit is decreasing in productivity, it follows that net changes in the number of establishment is positively correlated with productivity. Further, since the probability of a positive shock to productivity is increasing in productivity, changes in productivity are also correlated with 
net changes in the number of establishments. These results show how changes in productivity and size are related to changes in number of regions. 